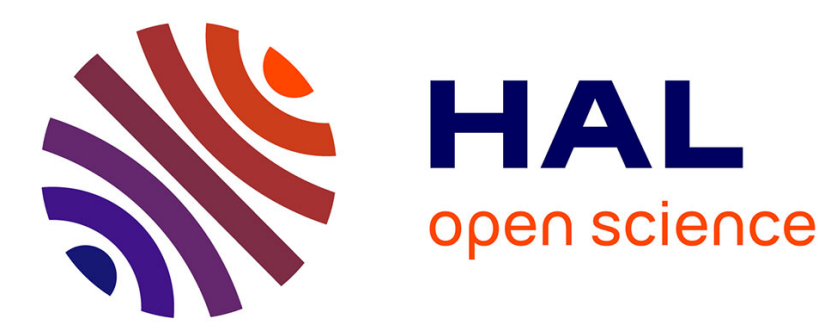

\title{
Synthesis of a Helical Bilayer Nanographene
}

Paul Jameson Evans, Jiangkun Ouyang, Ludovic Favereau, Jeanne Crassous, Israel Fernández, Josefina Perles Hernáez, Nazario Martín

\section{To cite this version:}

Paul Jameson Evans, Jiangkun Ouyang, Ludovic Favereau, Jeanne Crassous, Israel Fernández, et al.. Synthesis of a Helical Bilayer Nanographene. Angewandte Chemie International Edition, 2018, 57 (23), pp.6774-6779. 10.1002/anie.201800798 . hal-01711791

\section{HAL Id: hal-01711791 \\ https://hal.science/hal-01711791}

Submitted on 6 Jul 2018

HAL is a multi-disciplinary open access archive for the deposit and dissemination of scientific research documents, whether they are published or not. The documents may come from teaching and research institutions in France or abroad, or from public or private research centers.
L'archive ouverte pluridisciplinaire HAL, est destinée au dépôt et à la diffusion de documents scientifiques de niveau recherche, publiés ou non, émanant des établissements d'enseignement et de recherche français ou étrangers, des laboratoires publics ou privés. 


\title{
Synthesis of a Helical Bilayer Nanographene
}

\author{
Paul J. Evans, ${ }^{[a]}$ Jiangkun Ouyang, ${ }^{[c]}$ Ludovic Favereau, ${ }^{[\mathrm{c}]}$ Jeanne Crassous, ${ }^{[\mathrm{cc}]}$ Israel Fernández, ${ }^{[\mathrm{a}]}$ \\ Josefina Perles Hernáez, ${ }^{[\mathrm{d}]}$ and Nazario Martín ${ }^{\star[a, b]}$
}

This work is dedicated to Prof. Luis Castedo on the occasion of his $80^{\text {th }}$ birthday.

\begin{abstract}
A rigid, inherently chiral bilayer nanographene has been synthesized as both the racemate and enantioenriched $M$ isomer (with an ee of 93\%) in three steps from precedented helicenes. This folded nanographene is comprised of two hexa-perihexabenzocoronene layers fused to a [10]helicene, with an interlayer distance of $3.6 \AA$ as determined by $\mathrm{X}$-ray crystallography. The rigidity of the helicene linker forces the layers to adopt a nearly-aligned AAstacked conformation rarely observed in few-layer graphene. By combining the advantages of nanographenes and helicenes, we have constructed a bilayer system of 30 fused benzene rings that is also chiral, rigid, and remains soluble in common organic solvents. We present this as a molecular model system of bilayer graphene, with properties of interest in a variety of potential applications.
\end{abstract}

The bottom-up (benchtop, solution-phase) synthesis of large polycyclic aromatic hydrocarbons (PAHs) from small molecule precursors offers atomistic control unavailable in topdown (exfoliation, chemical vapor deposition, laser ablation, pyrolysis) approaches that rely on high temperatures or destruction of bulk material such as graphene or carbon nanotubes. ${ }^{[1]}$ This structural control allows the modification of related properties on demand. For example, constraining the $2 \mathrm{D}$ network of graphene in one or more dimensions, as in graphene nanoribbons and graphene quantum dots leads to the genesis and control of a HOMO-LUMO gap in an otherwise conducting material. ${ }^{[2]}$ Recently, the first examples of graphene quantum dots with chiroptical properties have also been reported. ${ }^{[3-4]}$ These nanographenes have been the subject of an explosion of research in recent years, showing promise the fields of photovoltaics ${ }^{[5-6]}$, and sensing..$^{[7]}$

The simplest member of the synthetic nanographene class is hexa-peri-hexabenzocoronene (HBC) which itself has been the subject of much research. ${ }^{[8-9]}$ Bending $\mathrm{sp}^{2}$ carbon frameworks out-of-plane, as in aromatic hoops, bowls, or spirals, leads to further control of the chirality, energy levels, and distribution of electron density while also mitigating solubility of large PAHs and leading to a class of unnatural bent and chiral

[a] Dr. P. J. Evans, Dr. I Fernández, Prof. Dr. N. Martín Departamento de Química Orgánica I, Facultad de Ciencias Químicas, Universidad Complutense de Madrid Ciudad Universitaria s/n 28040 Madrid (Spain)

E-mail: nazmar@quim.ucm.es

Homepage: www.nazariomartingroup.com

[b] Prof. Dr. N. Martín

IMDEA-Nanociencia, C/Faraday, 9, Campus de la Universidad

Autónoma de Madrid 28049 Madrid (Spain)

[c] Dr. J. Ouyang, Dr. L. Favereau, Dr. J. Crassous Institut des Sciences Chimiques de Rennes UMR 6226 CNRS - Univ. Rennes

Campus de Beaulieu

35042 Rennes Cedex (France)

[d] Dr. J. Perles

Single Crystal X-ray Diffraction Laboratory, Interdepartmental Research Service (SIdl)

Universidad Autónoma de Madrid, Cantoblanco

28049 Madrid (Spain)

Supporting information for this article is given via a link at the end of the document. nanographenes. ${ }^{[10-21]}$ Additionally, bilayer graphene, the twolayer homologue of graphene has useful, externally-tuneable electronic properties distinct from its single-layer relative such as band gap, spin-orbit interaction and exciton energies. ${ }^{[22-26]}$ Several devices exploiting these properties have been reported. ${ }^{[27-29]}$ Bilayer graphene also shows facile intercalation of metals. ${ }^{[30]}$ Recently, a bilayer graphene system demonstrated a lithium diffusion coefficient of $7 \times 10^{-5} \mathrm{~cm}^{2} \mathrm{~s}^{-1}$, ten times faster than graphite, revealing its potential as an ion transport material for energy storage. ${ }^{[31]}$ As such, we sought to combine all of these aspects into a new molecular system which could be considered a folded, chiral, bilayer nanographene. To maintain conjugation throughout the system and also provide a new entry into the emerging field of chiral nanographenes and $\pi$-extended helicenes $^{[32-36]}$ we chose helicene as the chiral $\mathrm{PAH}$ linker between HBC layers. The resulting target molecule is an unprecedented helical bilayer nanographene (HBNG).

The rapid synthesis of HBNG 5 was achieved in three synthetic steps from known ethynyl helicenes: racemic 1 or enantiopure (>99\% ee) $M-(-)-2$ (Scheme 1). ${ }^{[37]}$ Sonogashira coupling of 4-tert-butyliodobenzene added a benzene ring to each of the termini yielding 3 . When 2 was used as starting material, tetrabutylammonium fluoride was added to remove the trimethylsilyl protecting groups in situ. Diels-Alder cycloaddition of tetra-4-tert-butylphenyl cyclopentadienone to the alkynes followed by liberation of carbon monoxide gave the corresponding bis-pentaphenylphenyl helicenes 4 . The structure of the racemic product was unambiguously confirmed by X-ray diffraction crystallography (XRD, see supporting information, Figures S11-S13). Scholl cyclodehydrogenation using 2,3dichloro-5,6-dicyano-1,4-benzoquinone (DDQ) and trifluoromethanesulfonic acid $(\mathrm{TfOH})$ or $\mathrm{FeCl}_{3}$ assembled the two HBC layers and extended the helicene backbone from [6]- to [10]helicene, yielding the desired HBNG, 5 with a good overall yield (33\% for the racemate, $16 \%$ for the $M$-isomer). For $M-5$, circular dichroism spectroscopy confirmed the retention of configuration after each step (Figure 5 and supporting information, Figures S4-S5) and the overall enantiomeric excess was determined by chiral HPLC of $\mathbf{5}$ to be $93 \%$. Additionally, the tert-butyl sidechains render the final product sufficiently soluble to be characterized by ${ }^{1} \mathrm{H}$ and ${ }^{13} \mathrm{C}$ NMR yet crystalline enough to obtain an unambiguous structure by XRD.

HBNG 5 was crystallized by vapor diffusion of antisolvent methanol into a 1,2-dichloroethane solution. Interestingly, though the crystals were grown from a racemic mixture of $M$ and $P-5$, the obtained crystals showed the presence of only one of the isomers (shown here as the $M$ isomer, Figure 1). The nanographene crystallized in the non centro-symmetric $P 2_{1}$ space group with one molecule per asymmetric unit and packed into rows of molecules oriented in the [001] direction. Each of these rows is surrounded by four others in the [100] and [010] directions, where the molecules are located at a perpendicular angle owing to $\mathrm{C}-\mathrm{H}-\mathrm{m}$ interactions (see supporting information Figures S14-S17). 5 adopts the expected compact bilayer structure with an average centroid to centroid distance of 3.556 $\AA$ for the ten overlapping benzene rings on opposing layers, identical to the interlayer distance of $3.55 \AA$ in AA-stacked graphite and more densely packed than the parent [10]helicene $(3.82 \AA) .^{[38-39]}$ The two HBC layers are almost parallel, offset by $2.04^{\circ}$, and slip-stacked radially by $4.06^{\circ}$ with carbon atoms nearly aligned over each other as in AA-stacked graphite. The CVD synthesis of bilayer graphene yields two bernal AB-stacked layers and the high-energy AA arrangement is only observed in 
rare instances such as folded graphene or as the product of epitaxial growth on diamond (111). ${ }^{[9-42]}$ The alignment of the two layers in folded graphene systems dramatically influences the electronics of the material. ${ }^{[43-44]}$ In the only other example of a bilayer nanographene of which we are aware, a bilayer HBC cyclophane, the layers slip past each other due to the flexibility of the alkyl linkers. ${ }^{[5]}$ This packing in our system is achieved via the rigidity of the helicene linker. In future systems, by shortening or extending the helicene linker, the geometric relation of the two layers should be controllable.

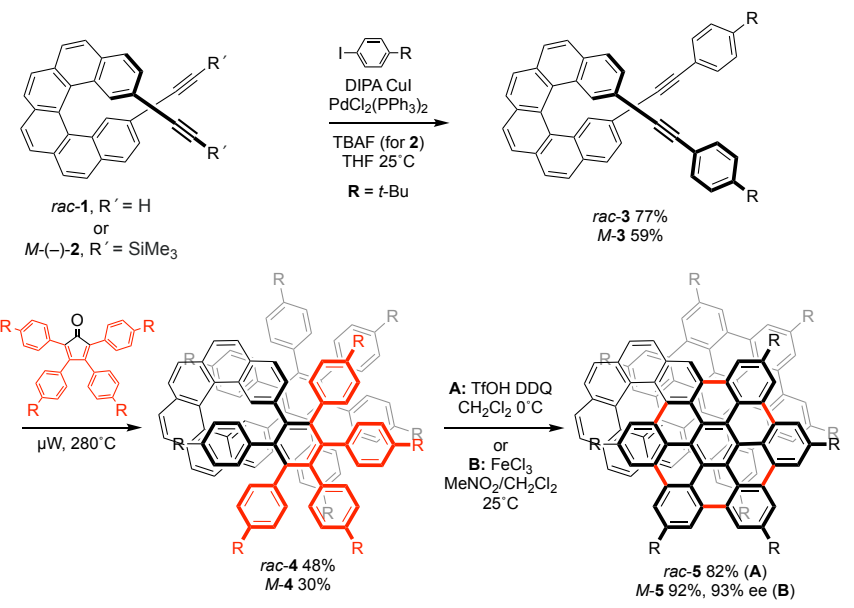

Scheme 1. Syntheses of racemic and enantiopure HBNG 5. Structures drawn as a single enantiomer for clarity and red highlights are used to illustrate important transformations.

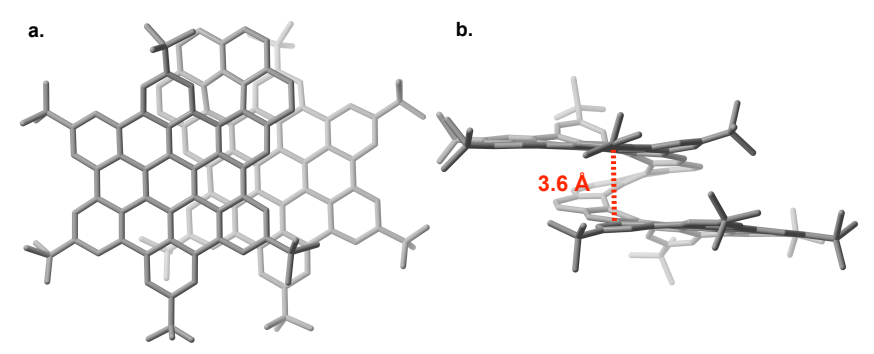

Figure 1. XRD structure of 5: offset top view (a), side view showing interlayer distance (b). Structures shown as the $M$ isomer with solvent and hydrogens excluded for clarity.

There are strong $\pi-\pi$ interactions between the five overlapping rings in each plane (see supporting information, Figure S15). The occurrence of this stabilizing intramolecular interaction can be computationally visualized by means of the NCIPLOT method ${ }^{[46]}$ As clearly shown in Figure 2, there exists a significant non-covalent attractive interaction (green surface) between the aromatic rings of both HBC layers which is mainly responsible for the peculiar arrangement of this species.

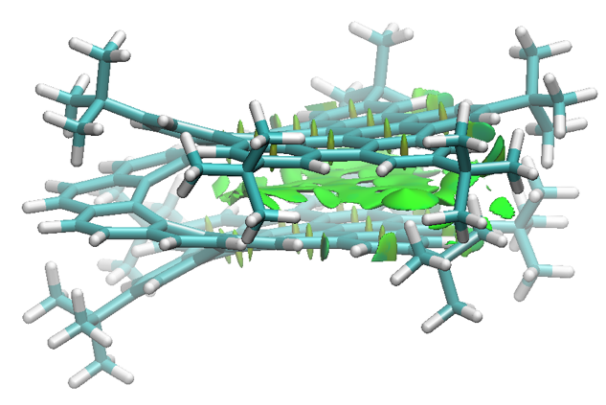

Figure 2. Contour plots of the reduced density gradient isosurfaces (density cutoff of 0.03 a.u.) for compound $\mathbf{5}$. The green surfaces indicate attractive noncovalent interactions.

The bilayer nanographene $\mathbf{5}$ absorbs strongly with two maxima at 360 and $376 \mathrm{~nm}$ and broadly out to $550 \mathrm{~nm}$ (Figure 3 ) giving it a vivid yellow-orange color in dichloromethane solution. This absorption is broader than the related hexa-tert-butylhexaperi-hexabenzocoronene ( $t$-BuHBC), a one-layer nanographene synthesized by the procedure reported by Rathore, due to the extended conjugation in our system. ${ }^{[47]}$ At increased concentration (ca. $10^{-5} \mathrm{M}$ ), the absorption broadens out past 650 $\mathrm{nm}$ likely due to aggregation (see supporting information, Figure S1), and the solution takes on a turbid brown appearance. The electronic excitation energy of $\mathbf{5}$ was calculated with timedependent (TD) DFT at the TD-B3LYP-D3/def2-SVP level. The calculations give a vertical excitation energy of $I_{\text {calc }}=535 \mathrm{~nm}$, which is in nice agreement with the experimentally observed value. This transition is associated with a one-electron excitation from the HOMO to the LUMO+1, both p-molecular orbitals fully delocalized between the HBC layers (see supporting information, Figure S18). The HBNG shows a strong and narrow emission with a maximum at $550 \mathrm{~nm}$ (Figure 3). The emission is featureless indicating the delocalization of the excitation in the molecule. The emission was observed to be most intense at 1.8 $\times 10^{-5} \mathrm{M}$ with quenching at higher concentrations, further supporting the formation of aggregates (see supporting information, Figures S2-S3).

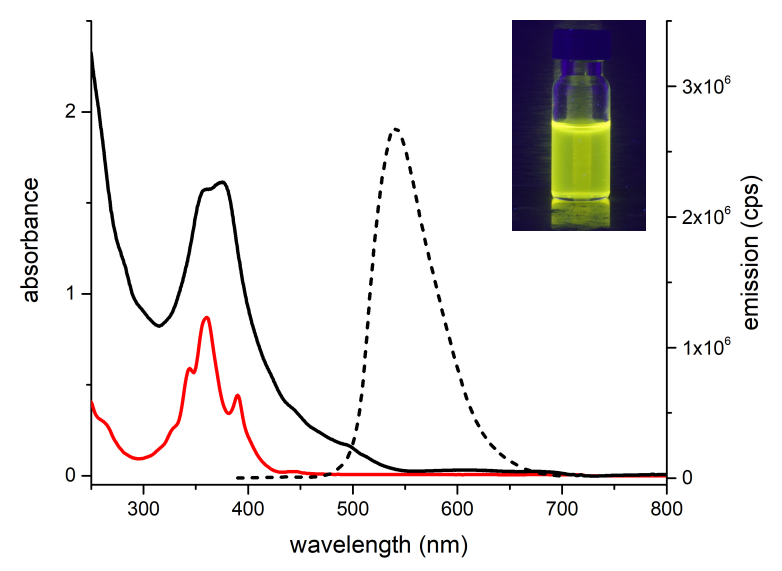

Figure 3. Absorption (solid black) and emission (dashed, excitation at $380 \mathrm{~nm}$ ) spectra of 5 at $1.8 \times 10^{-5} \mathrm{M}$ and $t$-BuHBC (solid red) in dichloromethane. Photo of a dichloromethane solution of 5 under $365 \mathrm{~nm}$ irradiation (inset). 
The Raman spectrum of 5 shows the $D(1350 \mathrm{~nm})$ and $G$ $(1600 \mathrm{~nm})$ band absorptions typical of a nanographene and identical to that of $t$-BuHBC (Figure 4). Any additional contribution from the helicene is overwhelmed by the wide and intense nanographene signals. ${ }^{[48]}$ The FTIR spectrum reveals the expected aromatic and alkyl $\mathrm{C}-\mathrm{C}$ and $\mathrm{C}-\mathrm{H}$ absorptions from $1460-1730 \mathrm{~cm}^{-1}$ and from $2850-3000 \mathrm{~cm}^{-1}$.

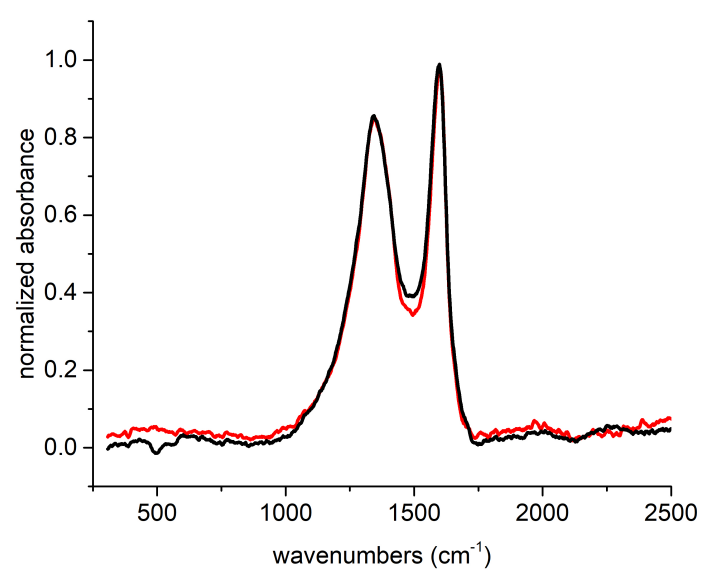

Figure 4. Raman spectra (excitation at $532 \mathrm{~nm}$ ) of $\mathbf{5}$ (black) and $t$-BuHBC (red).

A dilute dichloromethane solution of the enantioenriched M-5 shows a circular dichroism signal with a maximum at 380 $\mathrm{nm}$, likely arising from the helicene linker and a minimum at 450 $\mathrm{nm}$ attributed the HBC layers (bold red line, Figure 5). This confirms the inherently chirality and efficient transference of chirality throughout the molecule. At higher concentrations the spectrum evolves to show only one minimum at $520 \mathrm{~nm}$ indicating that, as expected, the superstructure of the aggregates in solution is also chiral.

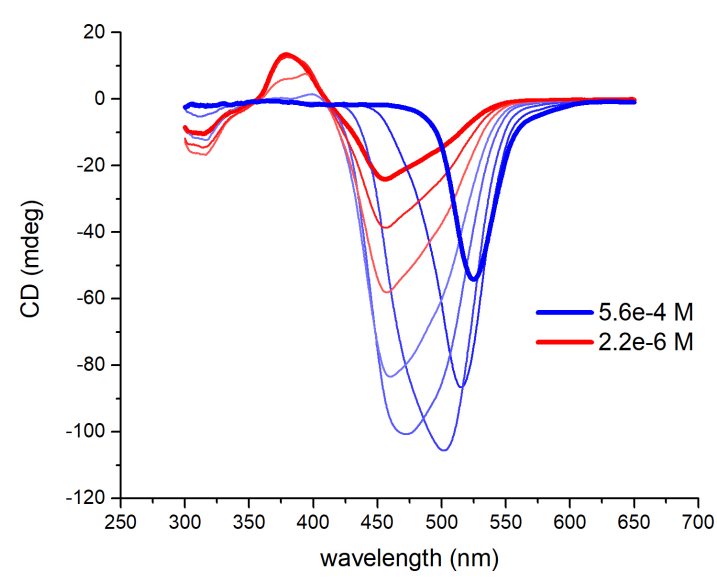

Figure 5. Circular dichroism spectrum of $M-5$ in dichloromethane with serial dilutions of $2^{\mathrm{x}}$ from $5.6 \times 10^{-4} \mathrm{M}$ (bold blue) to $2.2 \times 10^{-6} \mathrm{M}$ (bold red).

The electrochemical properties of $\mathbf{5}$ were explored by cyclic voltammetry in dichloromethane with tetrabutylammonium hexaflourophosphate as supporting electrolyte. Three reversible oxidation waves were observed at $0.09,0.40$ and $0.65 \mathrm{~V}$ versus a ferrocene-ferrocenium couple (Figure 6). The parent structures, $t$-BuHBC and alkynyl[6]helicene $M-(-)-2$ were also measured under the same experimental conditions (see supporting information, Figures S7-S8). $t$-BuHBC showed one reversible oxidation wave at $0.74 \mathrm{~V}$ and the helicene showed no oxidation within the solvent window. This comparison shows unequivocally that $\mathbf{5}$ is more easily oxidized than its constituent structures as a consequence of the extension of the $\pi$-system. The observed electrochemical trend nicely correlates with the computed energy of the corresponding HOMO (the orbital from which the electron is released): $-5.61 \mathrm{eV}(2)<-5.21 \mathrm{eV}(t-\mathrm{BuHBC})<-$ $4.95 \mathrm{eV}$ (5), thus showing that a more stabilized HOMO (i.e., more negative) is translated into a higher oxidation potential.

The extension of the $\pi$-delocalization in $\mathbf{5}$ can be further confirmed by visualizing the computed spin density in $5^{\circ+}$, the radical cation species formed upon the first electrochemical oxidation. As seen in Figure 7 , the unpaired electron in this species is fully delocalized over the entire $\pi$-system of the molecule, reflecting the electronic communication between both $\mathrm{HBC}$ layers in the newly prepared nanographene.

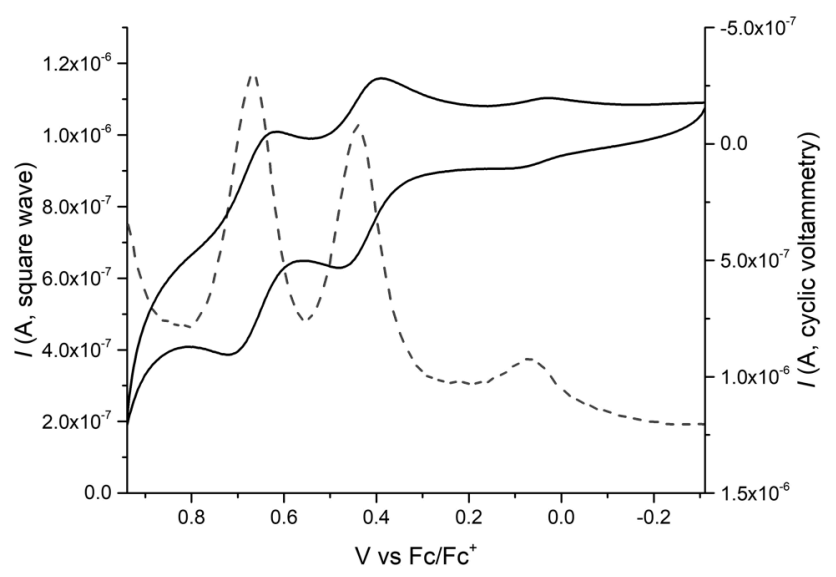

Figure 6. Cyclic voltammetry (solid) and squarewave voltammetry (dashed) analysis of $\mathbf{5}$ in dichloromethane at room temperature with tetrabutylammonium hexaflurophosphate supporting electrolyte, A glassy carbon working electrode, platinum wire counter electrode, and $\mathrm{Ag} / \mathrm{AgCl}$ reference electrode.

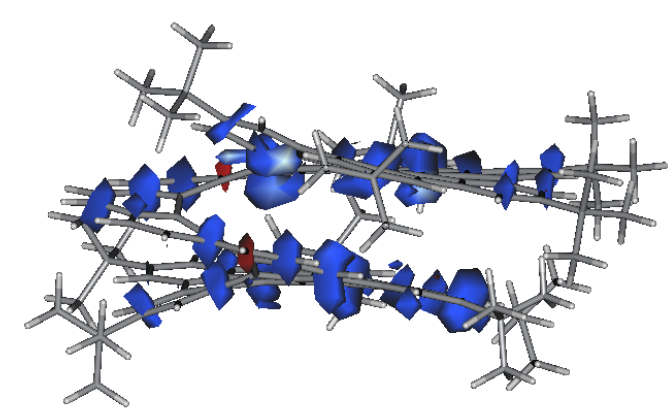

Figure 7. Calculated spin density of $\mathbf{5}^{\mathbf{*}}$ (isosurface value of $0.001 \mathrm{au}$ ). 
In conclusion, we have shown that the construction of $\mathrm{HBC}$ layers fused to a helicene backbone is a viable and efficient route to the syntheses of rigid, chiral, bilayer nanographene systems. In addition, when starting from an enantiopure helicene, the synthesis results in very little racemization, retaining a large enantiomeric excess (93\%) over three steps. With interest growing in bilayer graphene systems and twisted nanographenes alike, HBNG 5 provides a molecular platform with aspects of both thus opening the door to a new family of synthetic double-layer nanoforms of carbon. Further work to control the geometric relation of the layers and explore the intercalation of metals ${ }^{[49-50]}$ is underway.

\section{Acknowledgements}

Raman data were collected by Laura Rodríguez-Pérez (UCM). Nicolas Vanthuyne provided the HPLC purification of compound 2. PJE and NML acknowledge support from the European Research Council (ERC-320441-Chirallcarbon), the MINECO of Spain (project CTQ2014-52045-R) and the Comunidad de Madrid (PHOTOCARBON project S2013/MIT-2841); IF the Spanish MINECO-FEDER (Grants CTQ2016-78205-P and CTQ2016-81797-REDC); JO the Chinese Scholarship Council; and JF and JC the CNRS and the University of Rennes 1.

\section{Conflict of Interest}

The authors declare no conflict of interest.

Keywords: nanographene $\cdot$ arenes $•$ helicenes $•$ chirality $•$ bilayer graphene

[1] A. Narita, X.-Y. Wang, X. Feng, K. Mullen, Chem. Soc. Rev. 2015, 44, 6616-6643.

[2] X. Li, X. Wang, L. Zhang, S. Lee, H. Dai, Science 2008, 319, 12291232.

[3] N. Suzuki, Y. Wang, P. Elvati, Z.-B. Qu, K. Kim, S. Jiang, E. Baumeister, J. Lee, B. Yeom, J. H. Bahng, J. Lee, A. Violi, N. A. Kotov, ACS Nano 2016, 10, 1744-1755.

[4] M. Vazquez-Nakagawa, L. Rodriguez-Perez, M. A. Herranz, N. Martin, Chem. Commun. 2016, 52, 665-668.

[5] M.-L. Tsai, W.-C. Tu, L. Tang, T.-C. Wei, W.-R. Wei, S. P. Lau, L.-J. Chen, J.-H. He, Nano Lett. 2016, 16, 309-313.

[6] N. Martín, Adv. Energy Mater. 2017, 7, 1601102.

[7] S. Zhou, H. Xu, W. Gan, Q. Yuan, RSC Adv. 2016, 6, 110775-110788.

[8] V. J. Chebny, C. Gwengo, J. R. Gardinier, R. Rathore, Tetrahedron Lett. 2008, 49, 4869-4872.

[9] T. S. Navale, M. V. Ivanov, M. M. Hossain, R. Rathore, Angew. Chem. Int. Ed. 2018, 57, 790-794.

[10] J. Luo, X. Xu, R. Mao, Q. Miao, J. Am. Chem. Soc. 2012, 134, 1379613803.

[11] V. Berezhnaia, M. Roy, N. Vanthuyne, M. Villa, J.-V. Naubron, J. Rodriguez, Y. Coquerel, M. Gingras, J. Am. Chem. Soc. 2017, 139, 18508-18511.

[12] T. Fujikawa, Y. Segawa, K. Itami, J. Org. Chem. 2017, 82, 7745-7749.

[13] K. Y. Cheung, C. K. Chan, Z. Liu, Q. Miao, Angew. Chem. Int. Ed. 2017, 56, 9003-9007.

[14] W. Yang, G. Longhi, S. Abbate, A. Lucotti, M. Tommasini, C. Villani, V. J. Catalano, A. O. Lykhin, S. A. Varganov, W. A. Chalifoux, J. Am. Chem. Soc. 2017, 139, 13102-13109.
[15] U. H. F. Bunz, S. Menning, N. Martín, Angew. Chem. Int. Ed. 2012, 51, 7094-7101.

[16] S. H. Pun, C. K. Chan, J. Luo, Z. Liu, Q. Miao, Angew. Chem. Int. Ed. 2018, doi:10.1002/anie.201711437.

[17] T. Hosokawa, Y. Takahashi, T. Matsushima, S. Watanabe, S. Kikkawa, I. Azumaya, A. Tsurusaki, K. Kamikawa, J. Am. Chem. Soc. 2017, 139, 18512-18521.

[18] Y. Hu, X.-Y. Wang, P.-X. Peng, X.-C. Wang, X.-Y. Cao, X. Feng, K. Müllen, A. Narita, Angew. Chem. Int. Ed. 2017, 56, 3374-3378.

[19] K. Kato, Y. Segawa, L. T. Scott, K. Itami, Angew. Chem. Int. Ed., doi: 10.1002/anie.201711985.

[20] M. Daigle, D. Miao, A. Lucotti, M. Tommasini, J.-F. Morin, Angew. Chem. Int. Ed. 2017, 56, 6213-6217.

[21] M. Ferreira, G. Naulet, H. Gallardo, P. Dechambenoit, H. Bock, F. Durola, Angew. Chem. Int. Ed. 2017, 56, 3379-3382.

[22] Y. Zhang, T.-T. Tang, C. Girit, Z. Hao, M. C. Martin, A. Zettl, M. F. Crommie, Y. R. Shen, F. Wang, Nature 2009, 459, 820.

[23] L. Ju, L. Wang, T. Cao, T. Taniguchi, K. Watanabe, S. G. Louie, F. Rana, J. Park, J. Hone, F. Wang, P. L. McEuen, Science 2017, 358, 907-910.

[24] Y. Hao, L. Wang, Y. Liu, H. Chen, X. Wang, C. Tan, S. Nie, J. W. Suk, T. Jiang, T. Liang, J. Xiao, W. Ye, C. R. Dean, B. I. Yakobson, K. F. McCarty, P. Kim, J. Hone, L. Colombo, R. S. Ruoff, Nat. Nanotechnol. 2016, 11,426

[25] M. Gmitra, J. Fabian, Phys. Rev. Lett. 2017, 119, 146401.

[26] J. Y. Khoo, A. F. Morpurgo, L. Levitov, Nano Lett. 2017, 17, 7003-7008.

[27] H. Overweg, H. Eggimann, X. Chen, S. Slizovskiy, M. Eich, R. Pisoni, Y. Lee, P. Rickhaus, K. Watanabe, T. Taniguchi, V. Fal'ko, T. Ihn, K. Ensslin, Nano Lett. 2018, 18, 553-559.

[28] H. Qin, J. Sun, S. Liang, X. Li, X. Yang, Z. He, C. Yu, Z. Feng, Carbon 2017, 116, 760-765.

[29] P. S. Mahapatra, K. Sarkar, H. R. Krishnamurthy, S. Mukerjee, A. Ghosh, Nano Lett. 2017, 17, 6822-6827.

[30] S. Ichinokura, K. Sugawara, A. Takayama, T. Takahashi, S. Hasegawa, ACS Nano 2016, 10, 2761-2765.

[31] M. Kühne, F. Paolucci, J. Popovic, P. M. Ostrovsky, J. Maier, J. H. Smet, Nat. Nanotechnol. 2017, 12, 895.

[32] W. H. Laarhoven, R. J. F. Nivard, Tetrahedron 1976, 32, 2445-2450.

[33] A.-C. Bédard, A. Vlassova, A. C. Hernandez-Perez, A. Bessette, G. S. Hanan, M. A. Heuft, S. K. Collins, Chem. Eur. J. 2013, 19, 1629516302.

[34] M. Buchta, J. Rybáček, A. Jančařík, A. A. Kudale, M. Buděšínský, J. V. Chocholoušová, J. Vacek, L. Bednárová, I. Císařová, G. J. Bodwell, I. Starý, I. G. Stará, Chem. Eur. J. 2015, 21, 8910-8917.

[35] J.-Y. Hu, A. Paudel, N. Seto, X. Feng, M. Era, T. Matsumoto, J. Tanaka, M. R. J. Elsegood, C. Redshaw, T. Yamato, Org. Biomol. Chem. 2013, 11, 2186-2197.

[36] N. J. Schuster, D. W. Paley, S. Jockusch, F. Ng, M. L. Steigerwald, C. Nuckolls, Angew. Chem. Int. Ed. 2016, 55, 13519-13523.

[37] E. Anger, M. Srebro, N. Vanthuyne, L. Toupet, S. Rigaut, C. Roussel, J. Autschbach, J. Crassous, R. Réau, J. Am. Chem. Soc. 2012, 134, 15628-15631.

[38] L. Rulišek, O. Exner, L. Cwiklik, P. Jungwirth, I. Starý, L. Pospišil, Z. Havlas, J. Phys. Chem. C 2007, 111, 14948-14955.

[39] J.-K. Lee, S.-C. Lee, J.-P. Ahn, S.-C. Kim, J. I. B. Wilson, P. John, J. Chem. Phys. 2008, 129, 234709.

[40] Z. Liu, K. Suenaga, P. J. F. Harris, S. lijima, Phys. Rev. Lett. 2009, 102, 015501.

[41] K. Yan, H. Peng, Y. Zhou, H. Li, Z. Liu, Nano Lett. 2011, 11, 1106-1110.

[42] X. Chen, R. Xiang, P. Zhao, H. An, T. Inoue, S. Chiashi, S. Maruyama, Carbon 2016, 107, 852-856.

[43] B. Wang, M. Huang, N. Y. Kim, B. V. Cunning, Y. Huang, D. Qu, X. Chen, S. Jin, M. Biswal, X. Zhang, S. H. Lee, H. Lim, W. J. Yoo, Z. Lee, R. S. Ruoff, Nano Lett. 2017, 17, 1467-1473.

[44] J. M. B. Lopes dos Santos, N. M. R. Peres, A. H. Castro Neto, Phys. Rev. Lett. 2007, 99, 256802. 
[45] M. D. Watson, F. Jäckel, N. Severin, J. P. Rabe, K. Müllen, J. Am. Chem. Soc. 2004, 126, 1402-1407.

[46] E. R. Johnson, S. Keinan, P. Mori-Sánchez, J. Contreras-García, A. J. Cohen, W. Yang, J. Am. Chem. Soc. 2010, 132, 6498-6506.

[47] R. Rathore, C. L. Burns, J. Org. Chem. 2003, 68, 4071-4074.
[48] M. Carminati, L. Brambilla, G. Zerbi, K. Müllen, J. Wu, J. Chem. Phys. 2005, 123, 144706.

[49] T. J. Katz, J. Pesti, J. Am. Chem. Soc. 1982, 104, 346-347.

[50] A. Sudhakar, T. J. Katz, J. Am. Chem. Soc. 1986, 108, 179-181. 
WILEY-VCH

Entry for the Table of Contents (Please choose one layout)

Layout 2:

\section{COMMUNICATION}

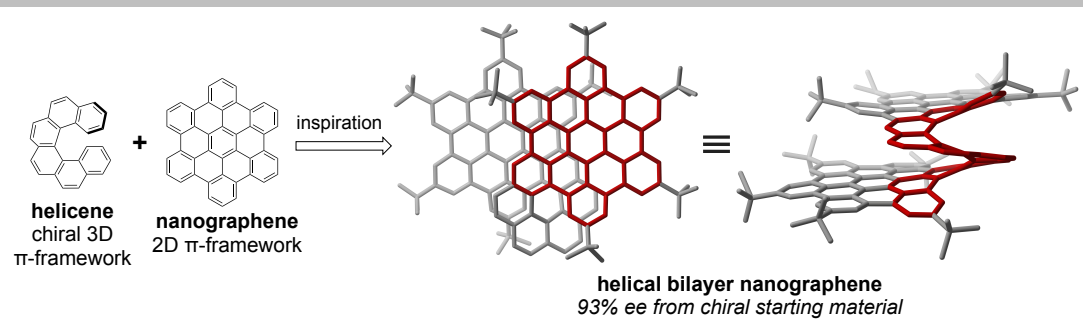

The next level in chiral nanographenes! An inherently chiral bilayer nanographene with a helicene linker has been synthesized as the racemate and the $M$ isomer with $93 \%$ ee. The synthesis, DFT analysis, X-ray structure, and electrochemical and photophysical properties of this first member of a new family of twisted double-layer polyaromatic hydrocarbons is presented.
Paul J. Evans, Jiangkun Ouyang, Ludovic Favereau, Jeanne Crassous, Israel Fernández, Josefina Perles Hernáez, and Nazario Martín

Page No. - Page No.

Synthesis of a Helical Bilayer Nanographene 